\title{
The Influence of Thermal Behaviour to Composites Based on Cotton Tissue and Unsaturated Polyester Resin
}

\author{
VIRGIL GEAMAN ${ }^{1}$, MIHAI ALIN POP ${ }^{1 *}$, IRINEL RADOMIR ${ }^{1}$, AUGUSTIN SEMENESCU ${ }^{2}$, \\ BOGDAN FLOREA ${ }^{2}$, OANA ROXANA CHIVU ${ }^{3}$ \\ ${ }^{1}$ Transilvania University of Brasov, 29 Eroilor Blvd., 500036, Brasov, Romania \\ ${ }^{2}$ University Politehnica of Bucharest, Faculty of Material Science and Engineering, 313 Splaiul Independentei, 060021, Bucharest, \\ Romania \\ ${ }^{3}$ University Politehnica of Bucharest, Faculty of Engineering and Management of Technological Systems, 313 Splaiul Independentei, \\ 060021, Bucharest, Romania
}

\begin{abstract}
The work focuses some experimental aspects concerning the weight gain, differential scanning calorimetric (DSC), dilatometer analysis (DIL) and thermo - gravimetric analysis (TG/DTA) for a composite material, based on cotton tissue and unsaturated polyester resin noted MCTDBN and immersed in salt water with $5 \% \mathrm{NaCl}$ for 90 days. Following these analyzes are emphasized the thermal expansion, temperature glass transition and thermal decomposition. Before of thermal analysis, the treated specimens were dried in an oven at temperature of $30^{\circ} \mathrm{C}$ for several days. The paper presents also the effect of salt solution treatment and comparative analysis between untreated and treated composites.
\end{abstract}

Keywords: thermal behavior, resin reinforced, cotton, $\mathrm{NaCl}$

\section{Introduction}

Cotton is one of the most important natural fibers employed in the textile industries and also one of the most flammable fibers with low limiting oxygen index $(\mathrm{LOI}=18.4 \%)$ and onset of pyrolysis at $350^{\circ} \mathrm{C}$ [1]. The cellulose, hemicellulose and lignin degradation caused by increasing of temperature was considered by Nabi Sahed and Jog a crucial aspect for the thermal stability of natural fiber reinforced polymer composites [2]. Polymer matrices are most commonly used because of cost efficient, ease of fabricating complex parts with less tooling cost and also having excellent room temperature properties when compared to other matrices. Thermoset matrices are formed due to an irreversible chemical transformation of resin into an amorphous cross-linked polymer matrix [3].

Moisture uptake in polymer matrix composites has a deleterious effect on their characteristic properties [4]. Therefore, it is important to study in detail the water absorption behavior in order to estimate not only the consequences that the water absorbed may have, but also the durability of natural fibers composites aged under water [5]. Thermal expansion of polymers is influenced by an isotropic building structure and by the large free volume between weakly bound molecular chains for primary and secondary phases of glass transition which also contribute to thermal expansion $[6,7]$.

\section{Matherial and methods}

Cotton and unsaturated polyester resin (NESTRAPOL 455-60) were used for experiments. The composite samples are based on cotton/unsaturated polyester with one layer of cotton fiber obtained by hand lay-up method.

\subsection{Salt treatment measurements}

Weight gain test of cotton/unsaturated polyester were left to soak for 90 days in salt water with 5\% $\mathrm{NaCl}$. In order to measure the weight gain, the specimens were taking out and periodically weighed

\footnotetext{
*email: mihai.pop@unitbv.ro
} 
with a precise electronic balance (with an accuracy of 3 decimals), for 12 days every $24 \mathrm{~h}$, for monitoring the variation of the sample mass during the ageing process. The absorption process was expressed with the relation [8]:

$$
M_{t}=\left(\frac{W_{t}-W_{o}}{W_{o}}\right) * 100 ; \quad[\%]
$$

where: $W_{t}$ - weight of the sample at time $t$;

$W_{o}$ - initial weight of sample.

In Figure 1 are shown the average weight gain of five specimens. From the salt solution absorption curve, it is shown that the weight gain increases with increasing immersion time in the first 12 days for each sample. The study on the weight gain of the composite was found with maximum absorption for composites with one layer with $12,31 \%$.

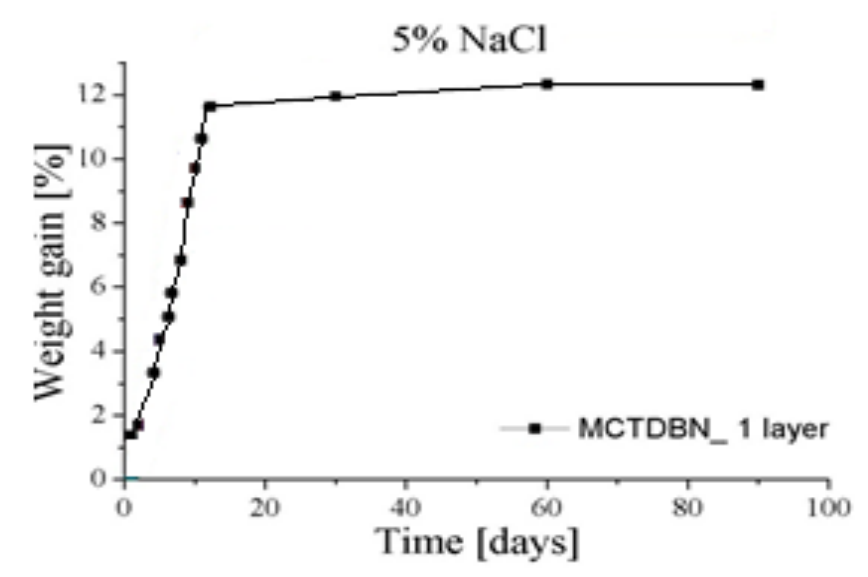

Figure 1. Curve of weight gain for MCTDBN composites immersed in salt water

It is also observed that the water absorption attains equilibrium after 60 days at which stage the composite have attained saturation point as far as water absorption is concerned. In $\mathrm{NaCl}$ solution, two mechanisms can be imagined as contributing towards the overall hygrothermal effects on the reinforced plastics. The expansion of the matrix due to absorption may cause tensile stresses in the fibers and compressive stresses in the matrix which is similar to differential thermal expansion and the diffusing molecules of water and sodium chloride may strain or rupture the intermolecular bond in the matrix and at the interface. It has been found that there is either preferential diffusion of $\mathrm{NaCl}$ molecules or that of presence of salt creates an additional capacity in the specimen to accommodate more water $[9,10,11]$.

\subsection{Differential scanning calorimetry analysis (DSC/DDSC)}

The differential scanning calorimetry (DSC) was performed using DSC F3 MAIA equipment. The weight of the samples are between $15-20 \mathrm{mg}$, were heated at a constant rate $10^{\circ} \mathrm{C} / \mathrm{min}$, up to $200^{\circ} \mathrm{C}$ under nitrogen atmosphere. The figure 2 is presented the glass transition $\left(\mathrm{T}_{\mathrm{g}}\right)$ diagrams between untreated and treated MCTDBM composite. The curves DDSC represent the first derivative of DSC curves. 


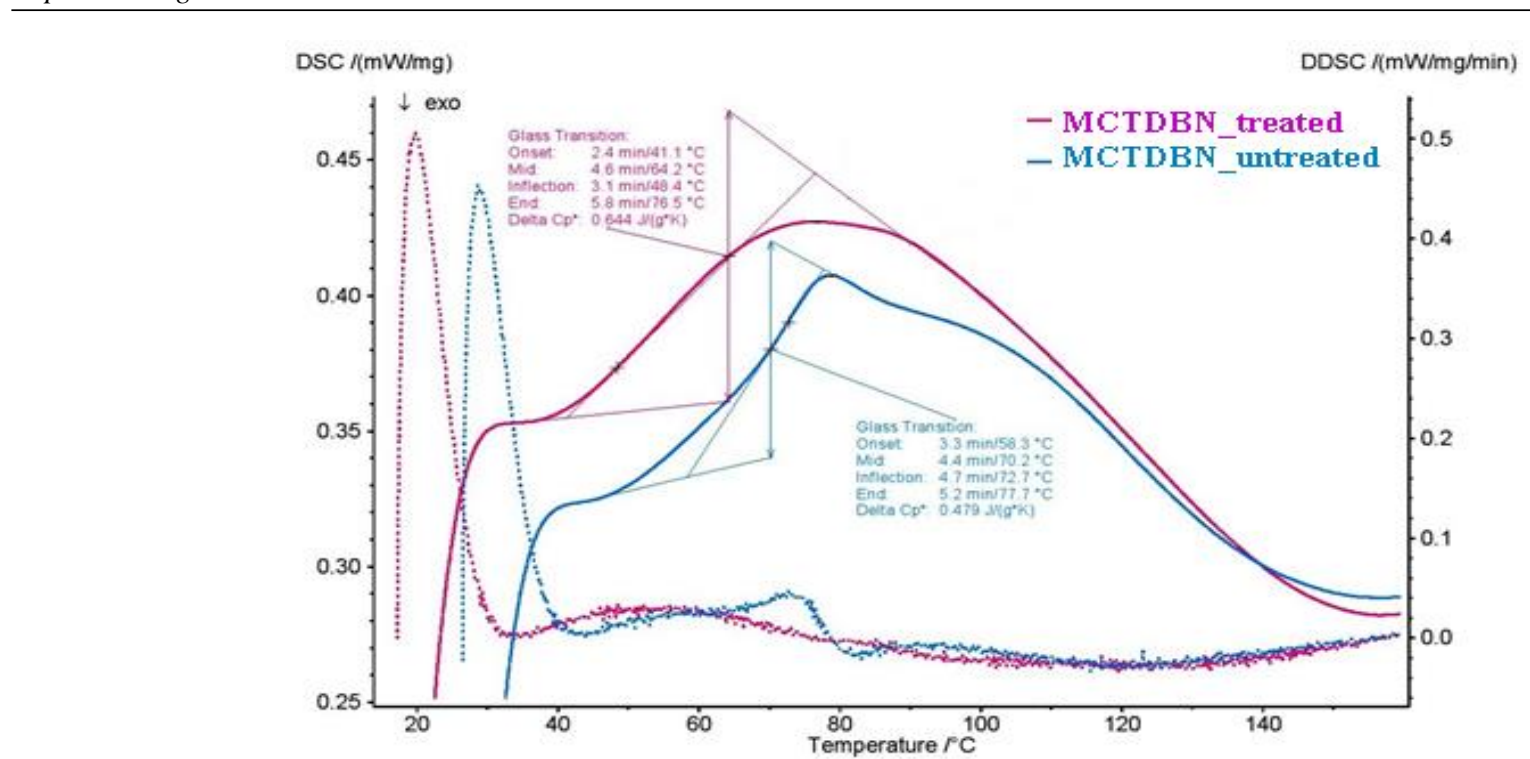

Figure 2. Glass transition diagrams for untreated and treated MCTDBN composite

To understand the glass transition $\left(T_{g}\right)$ the temperature is assigned as a region above amorphous (non-crystalline) materials which are fluid or rubbery, simply frozen in a disordered state [9]. Analyzing the temperature glass transition curves of treated and untreated composites is significant. We can say that a factor that led to lower temperature transition is hydrophilic for natural fiber, even the composite was dried several days. So, the drying process did not occur entirely causing the decrease of temperature glass transition.

\subsection{Dilatometry analysis (DIL)}

The thermal expansion was performed using DIL-75/1400 equipment. The samples used for dilatometry were made as solid cylindrical specimens measuring $6 \mathrm{~mm}$ in diameter and a length of 10 $\mathrm{mm}$. In the dilatometry experiments, the samples were heated (one thermal cycle) at a rate of $10^{\circ} \mathrm{C} / \mathrm{min}$ at room temperature up to $200^{\circ} \mathrm{C}$. Before thermal analysis the treated samples were kiln-dried at controlled temperature of $30^{\circ} \mathrm{C}$ for several days [10].

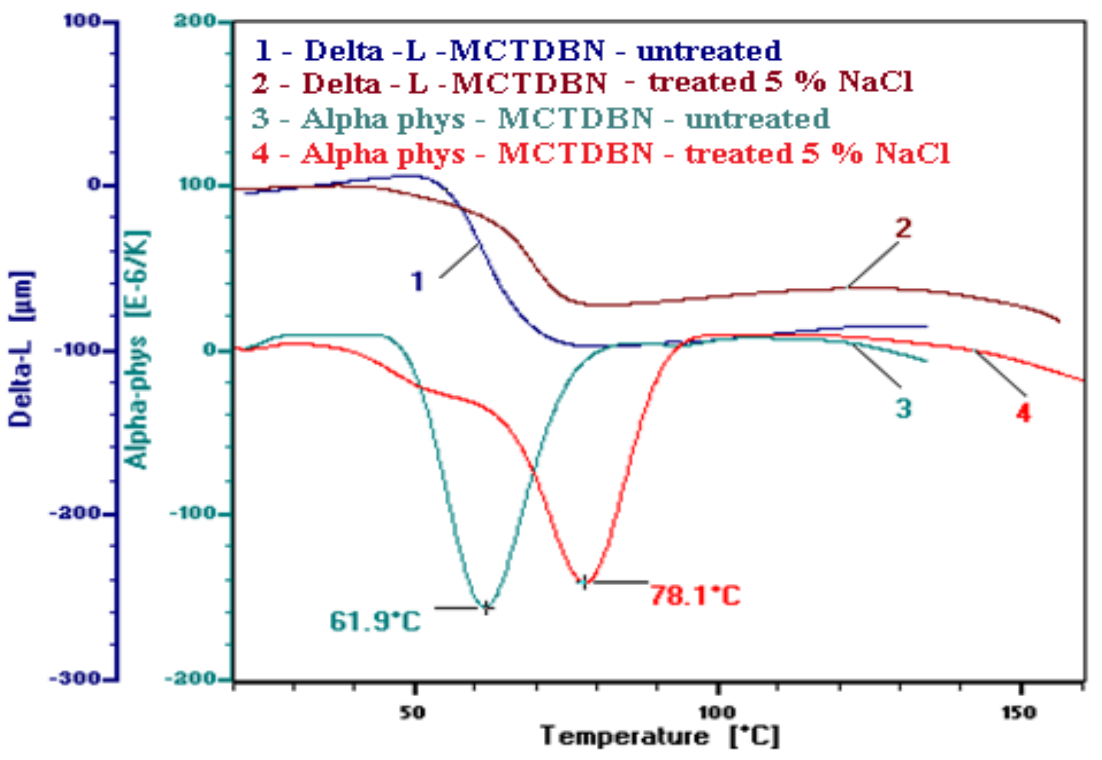

Figure 3. Coefficient of thermal expansion of untreated and treated MCTDBN composite 
In figure 3 are shown the curves corresponding to thermal dilatation and coefficient of thermal expansion for treated and untreated composites where the temperature values corresponds to negative coefficient of thermal expansion. It can be seen the significant peaks that corresponds to $61.9^{\circ} \mathrm{C}$ and $78.1^{\circ} \mathrm{C}$ temperatures with a thermal shrinkage in composite that present a thermal instability. If we compare the temperatures of thermal coefficient expansion for untreated and treated composites it is observed that the treated composite is slightly more stable. Thermal dilatation occurs in the samples treated at a higher temperature compared to the untreated ones, so they are more stable up to a higher temperature (from 61.9 to $78.1^{\circ} \mathrm{C}$ ).

\subsection{Thermo - gravimetric analysis (TG/DTA)}

The thermal analysis was studied using the STA 449 F3 JUPITER analyzer instrument. The thermo- gravimetric curves and differential thermo-gravimetric curves are shown in Figure 4. The temperature range used was from 25 to $500^{\circ} \mathrm{C}$. The heating rate was $10^{\circ} \mathrm{C} / \mathrm{min}$ under nitrogen atmosphere at a gas flow rate of $20 \mathrm{~mL} / \mathrm{min}$.

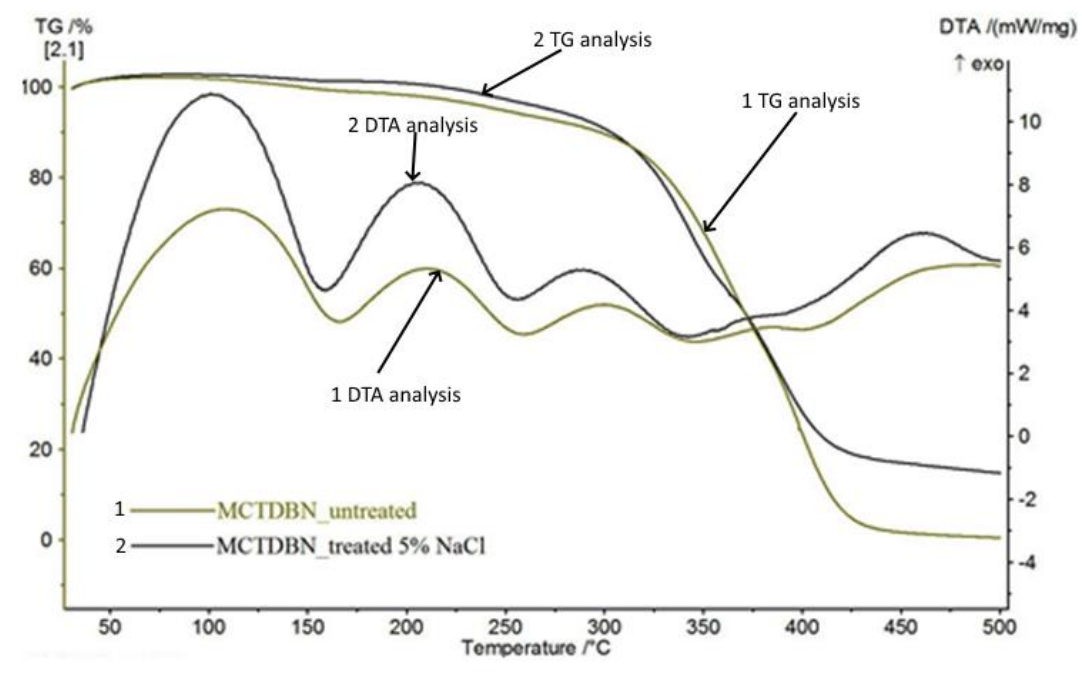

Figure 4. Mass degradation of untreated and treated MCTDBN composites

Comparing the DTA curves of treated and untreated samples, the results are shown that the degradation took place in 3 stages. First stage represents an evaporation of water from the fiber in the temperature range of $50-150^{\circ} \mathrm{C}$. Between temperatures of 200 to $300^{\circ} \mathrm{C}$ most of the constituents of the fiber decomposed and volatiles of resin are evaporating. The DTA curves endothermic gives peaks to about $350^{\circ} \mathrm{C}$ corresponding to depolymerisation for each treated and untreated composites. The mass degradation of treated and untreated MCTDBN composites is presented in Table 1.

Table. 1. Mass degradation and temperature of treated and untreated MCTDBN composites

\begin{tabular}{|c|c|c|c|c|c|c|c|c|c|c|}
\hline Sample & \multicolumn{10}{|c|}{$M C T D B N$} \\
\hline Properties & \multicolumn{5}{|c|}{ Untreated } & \multicolumn{5}{|c|}{ Treated with $5 \% \mathrm{NaCl}$} \\
\hline Temperature $\left[{ }^{\circ} \mathrm{C}\right]$ & 300 & 350 & 400 & 450 & 500 & 300 & 350 & 400 & 450 & 500 \\
\hline Mass loss [\%] & $\begin{array}{c}10.3 \\
7\end{array}$ & 31.99 & 76,61 & 98,39 & 99.19 & 9.12 & 37.29 & 71.72 & 82.92 & 85.59 \\
\hline Residual mass [\%] & \multicolumn{5}{|c|}{0.81} & \multicolumn{5}{|c|}{14.41} \\
\hline
\end{tabular}

Comparing the degradation processes the mass loss and thermal stability are different. The treated composites present a thermal stability. 
The residual mass between samples is different which confirms that the drying treatment by water evaporation can make salt particles to retain to their position in fiber.

\section{Conclusions}

The idea of composites based on natural fibers vs. unsaturated polymer is based on superior behavior on reinforcing filler and matrix.

The treatment with salt solution produce effects on the thermal stability of the friendly composites and to reduce the absorption of the cotton fiber.

The use of eco-composites has clear advantages for environmental protection and sustainable development.

Acknowledgements: We hereby acknowledge the structural founds project PRO-DD (POS-CCE, O.2.2.1., ID 123, SMIS 2637, ctr. No 11/2009) for providing the infrastructure used in this work.

\section{References}

1.SHARIATINIA Z., JAVERI N., SHEKARRIZ S., Carbohydrate Polymers 1182015183.

2.MONTEIRO S.N., CALADO V., RODRIQUEZ R.J.S., MARGEM F.M., Material Science \& Engineering, 201217.

3.SARAVANA D.B., MOHAN C.G.K., IAENG, Proceedings of the World Congress on Engineering, Vol.III 2013.

4.SEKI Y., SEVER K., SANKANAT M., SEN I., Aral A., IATS, 2011368.

5.SAMPATHKUMAR D., PUNYAMURTH R., VENKATESHAPPA S., BENNEHALLI B., Journal of Applied Sciences Research, 8, nr. 11, 2012, p. 5298.

6.ALDRIGHETTI C., TASSONE P., CIARDELLI F., RUGGERI G., Polymer degradation and Stability, 90.2 (2005) 346.

7.S.F. IBRAHIM, K.E. SHADY, Thermal analysis and characterization of some cellulosic fabric dyed by a new natural dye and mordant with different mordents, International Journal of chemistry, pp.4054, 2011.

8.H. ALAMRI, I.M. LOW, Effect of water absorption on the mechanical properties of nanoclay filled recycled cellulose fiber reinforced epoxy hybrid nanocomposites, Composites (44), pp. 23-31, 2013.

9.S. K. REGE, S.C. LAKKAD "Effect of Salt Water on Mechanical Properties of Fibre Reinforced Plastics, Fiber Science and Technology, Vol 19, pp. 317 - 324, 1983.

10.R.F. COTERLICI et al. - Thermal Analysis Studies Regarding the Eco-Composites Based on Jute by Applying Salinity Treatment. REV.CHIM. (Bucharest). Vol. 67 No. 10, 2016 pp. 2049 - 2052.

R.F. Coterlici, Geaman V. - The effect of salt water treatment on bending test of jute tissue/epoxy composites. The $5^{\text {th }}$ International Conference COMAT 2014 - Brasov. CD pp.46-50

Manuscript received: 21.09.2019 